\title{
The effects of machining parameters on machining time in piezoelectric self-adaptive micro-EDM
}

\author{
Fu Xiuzhuo ${ }^{1, a}$ Gao Liying ${ }^{1, b}$ Zhang Qinhe ${ }^{2, c}$ \\ ${ }^{1}$ School of Mechanical \& Automotive Engineering, Shandong Polytechnic University, Jinan \\ ${ }^{2}$ School of Mechanical Engineering, Shandong University, Jinan \\ a zhuozicom@126.com ${ }^{\mathrm{b}}$ gaoliying2008@126.com czhangqh@sdu.edu.cn
}

Keywords: Micro-EDM, Self-adaptive, Piezoelectric actuator; machining time

\begin{abstract}
A new piezoelectric self-adaptive micro electrical discharge machining system, based on inverse piezoelectric effect, was developed in this paper to improve stability of micro-EDM process The Working mechanism and working process of this new technology were illustrated. In this new technology, the piezoelectric actuator was used as the micro driven system to control the discharge gap distance depending on the discharge state. This paper presents an investigation on the effects of machining parameters on machining efficiency in piezoelectric self-adaptive discharge machining. The effects of machining parameters such as open voltage, capacitance, resistance, spindle rotational speed and initial feed speed have been analyzed on machining efficiency by using signal to noise analysis method based on orthogonal experiment.
\end{abstract}

\section{Introduction}

Micro-EDM is a precision machining process for machining micro-structures; its material removal mechanism is based on melting and vaporizing material with the heat and pressure generated by electrical discharge, so it can machine any type of conductive material, regardless of its hardness ${ }^{[1-3]}$. The basic characteristic of micro-EDM process is similar to that of normal EDM process ${ }^{[4]}$, but higher requirements were set on the precision and sensitivity of electrode drive system for micro-EDM system because of the reduction of discharge gap and discharge energy. In this paper, in order to improve the process stability and achieve better micro-EDM performance, a new piezoelectric self-adaptive micro-EDM technology, based on inverse piezoelectric effect, was presented in this paper.

The working mechanism and micro-EDM device of this new technology is different from the normal micro-EDM, it has the special characteristics. The work presented in this paper aims to study the influence of machining parameters on machining time of this new piezoelectric self-adaptive micro-EDM.

\section{Working mechanism}

The structural design and principle of the new device are different from the conventional micro-EDM devices. The working mechanism of piezoelectric self-adaptive micro-EDM technology is shown in Fig. 1. Piezoelectric actuator can feed forward with micro step and it is fixed on the macro-driven table which can feed forward with macro step. The DC power is connected not only with piezoelectric actuator but also with the tool electrode and workpiece, thus forms a parallel circuit in the circuit. This circuit forms an equivalent RC circuit because the piezoelectric actuator can be used as a capacitor. Its equivalent circuit is shown in Fig. 2(a). $C_{1}$ is piezoelectric actuator, its capacitance is $4.5 \mu \mathrm{F}, \mathrm{R}_{1}$ and $\mathrm{R}_{2}$ are current limiting resistances, $\mathrm{R}_{2}$ can limit the current of the piezoelectric actuator discharge circuit to protect the piezoelectric actuator from damage. The capacitance of the piezoelectric actuator is invariant, in order to alter the capacitance to adapt different machining criteria, an adjustable condenser is parallel connected with the piezoelectric actuator. The equivalent circuit is shown in Fig.2 (b). $\mathrm{C}_{2}$ is an adjustable condenser and the most energies used for discharging is provided by $\mathrm{C}_{2}$. In this circuit, the resistance $\mathrm{R} 2$ not 
only can protect the piezoelectric from damage because of heavy current, and at the same time, this resistance $\left(R_{2}\right)$ can change the following effect of piezoelectric actuator to ensure the machining process is always in optimum condition.

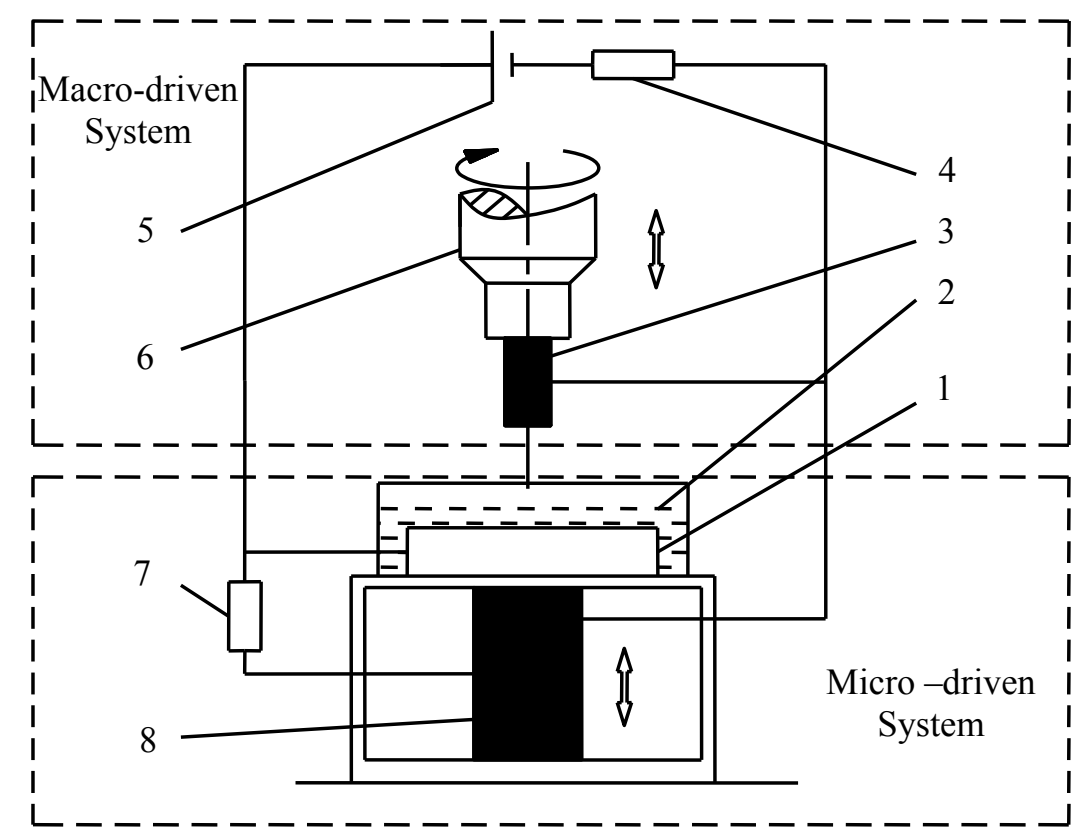

Fig.1 Working mechanism

1 Workpiece 2 Working medium 3 Electrode 4 Resistance 5 DC prower 6 Spindle 7 Resistance 8 Piezoelectric actuator

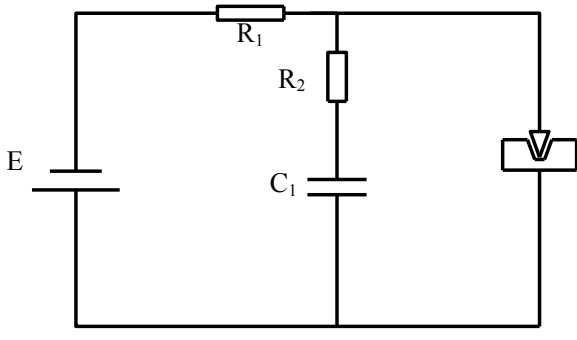

(a)

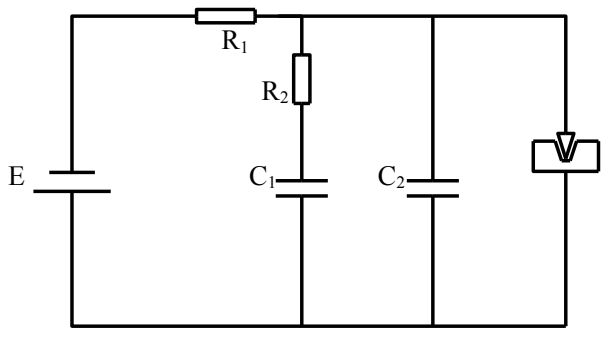

(b)

Fig.2 Equivalent-circuit diagram

E: DC power $\quad \mathrm{R}_{1}, \mathrm{R}_{2}$ : Resistance

$\mathrm{C}_{1}$ : Piezoelectric actuator $\mathrm{C}_{2}$ : Adjustable condenser

\section{Working process}

The working process of piezoelectric self-adaptive micro-EDM system is: First, the piezoelectric actuator $\left(\mathrm{C}_{1}\right)$ and adjustable capacitor $\left(\mathrm{C}_{2}\right)$ are connected with a DC power whose voltage can be regulated continuously from $0 \mathrm{~V}$ to $100 \mathrm{~V}$. When the power switch is closed, the capacitor and the piezoelectric actuator are charged by the DC power, the piezoelectric actuator will stretch forward because of the increase of its voltage The macro-driven table drives the electrode move forward, when the gap between electrode and workpiece achieves a best breakdown gap for discharging, a turn-on circuit is formed between electrode and workpiece and the discharge channel is formed, the capacitor $\left(\mathrm{C}_{2}\right)$ and piezoelectric actuator $\left(\mathrm{C}_{1}\right)$ will discharge instantaneously at the same time. The piezoelectric actuator retracts because of the sudden fall of voltage, and the workpiece will move backward with the piezoelectric actuator, the gap between electrode and workpiece becomes bigger and bigger, the discharging will be broken down and a discharge is completed; the capacitor $\left(\mathrm{C}_{2}\right)$ and piezoelectric actuator $\left(\mathrm{C}_{1}\right)$ will be charged again by the $\mathrm{DC}$ power soon after, the piezoelectric actuator protract once more, when the gap between electrode and workpiece achieves a best breakdown gap for discharging, a second discharging occurs. Go round and round, piezoelectric 
self-adaptive EDM will be implemented.

\section{Design of the experiments}

\section{Design factors selected.}

There are a large number of factors to consider within the EDM process, in this present study, because the following factors such as open voltage $(\mathrm{U})$, capacitance of adjustor condenser $\left(\mathrm{C}_{2}\right)$, resistance $\left(R_{1}, R_{2}\right)$, rotate speed of spindle $(n)$, initial feeding speed $(V)$ are the most widespread and used amongst in piezoelectric self-adaptive micro-EDM, these six factors have only been taken into account as design factors. In this study, to simplify the calculation process and statistics conveniently, machining time substitutes for machining efficiency

\section{Experimental design based on Taguchi method.}

Taguchi method is a powerful tool in the design of experiment methods, using the Taguchi method would markedly reduce the number of experiments, ${ }^{[5,6]}$. In this study, the experimental design was according to an $\mathrm{L}_{25}\left(4^{5}\right)$ orthogonal array based on the Taguchi method. The $\mathrm{S} / \mathrm{N}$ ratios are calculated from the observed values. In this study, the experimentally observed machining time value is "the lower the better" (LB). Therefore, the optimal observed machining time was the minimum value.

Based on the Taguchi method, the $\mathrm{S} / \mathrm{N}$ ratio calculation was decided as the "the lower the better, LB" as is given in the following equations ${ }^{[6]}$ :

$$
\text { LB: } \eta=-10 \lg \left(\frac{1}{n} \sum_{i=1}^{n} y_{i}^{2}\right)(d b)
$$

Where $\eta$ denotes the $\mathrm{S} / \mathrm{N}$ ratio calculated from the observed values, $y_{i}$ represents the experimentally observed value of the $i$ th experiment, and $n$ is the repeated number of each experiment. In this study, each experiment in the $\mathrm{L}_{25}$ array is conducted three times.

\section{Experimental conditions.}

The experimental work was conducted on the piezoelectric self-adaptive micro-EDM machine. The electrodes used in the present stuffy were tungsten with the diameter about $0.105 \mathrm{~mm}$. The workpiece materials used in the present study were tool steel with the thickness is $0.15 \mathrm{~mm}$. Special EDM oil was used as the dielectric fluid. In order to obtain better machining performances, the positive polarity machining by means of a positive electrical source connected to the workpiece, while a negative electrical source connected to the electrode. Table 1 presents the experimentally observed values, machining parameters and the levels of the machining parameters based on Taguchi method. The $\mathrm{S} / \mathrm{N}$ ratios were calculated from the experimental observed values according to Esq.(1).

Table 1 Machining parameters and levels

\begin{tabular}{ccccccc}
\hline \multirow{2}{*}{ Parameters } & \multirow{2}{*}{ Unit } & \multicolumn{5}{c}{ Level } \\
\cline { 3 - 7 } & & 1 & 2 & 3 & 4 & 5 \\
\hline Open voltage $\mathrm{U}$ & $\mathrm{V}$ & 40 & 50 & 60 & 70 & 80 \\
Capacitance $\mathrm{C}_{2}$ & $\mathrm{nF}$ & 2.2 & 4.7 & 10 & 14.7 & 3.3 \\
Resistance $\mathrm{R}_{1}$ & $\Omega$ & 100 & 300 & 1000 & 2200 & 4400 \\
Resistance $\mathrm{R}_{2}$ & $\Omega$ & 510 & 1000 & 2200 & 3400 & 5100 \\
Revolve speed n & $\mathrm{rpm}$ & 300 & 1000 & 3000 & 5000 & 10000 \\
Initial feeding speed V & $\mu \mathrm{m} / \mathrm{s}$ & 0.2 & 0.4 & 0.6 & 0.8 & 1.0 \\
\hline
\end{tabular}

\section{Result of experiments.}

The results of the experiments and the $\mathrm{S} / \mathrm{N}$ ratios of machining time are illustrated in table 2.

\section{Analysis of machining time}

Fig. 3 indicates that the effect of the machining parameters on the $\mathrm{S} / \mathrm{N}$ ratio of machining time. It shows that with the increase of open voltage, capacitance and initial feeding speed, the $\mathrm{S} / \mathrm{N}$ ratio of machining time is increasing, that is the machining time decreases with the increase of these three 
machining parameters. This is because in the piezoelectric self-adaptive micro-EDM processing, the open voltage and capacitance are the main factors which determine the discharge energy, with the increase of open voltage and capacitance the discharge energy is increased, so the machining efficiency is improved, which cause the machining time decrease. To some extent, the initial feeding speed of the spindle has an effect on the discharge frequency, when the initial feeding speed is small, the discharge frequency is low, so the machining efficiency is low and the machining time is high.

Table 2 Results of experiments and $\mathrm{S} / \mathrm{N}$ ratios of machining time

\begin{tabular}{|c|c|c|c|c|}
\hline \multirow{2}{*}{ No. } & \multicolumn{3}{|c|}{ Machining time $\mathrm{T} / \mathrm{min}$} & \multirow[t]{2}{*}{ S/N Ratio } \\
\hline & Test 1 & Test 2 & Test 3 & \\
\hline 1 & 11.55 & 11.19 & 11.28 & -21.09 \\
\hline 2 & 5.79 & 6.01 & 6.28 & -15.61 \\
\hline 3 & 5.46 & 5.61 & 5.44 & -14.81 \\
\hline 4 & 4.18 & 4.45 & 4.27 & -12.67 \\
\hline 5 & 6.12 & 6.83 & 6.35 & -16.18 \\
\hline 6 & 3.65 & 3.55 & 3.88 & -11.35 \\
\hline 7 & 11.13 & 10.57 & 11.21 & -20.81 \\
\hline 8 & 6.42 & 6.88 & 6.73 & -16.49 \\
\hline 9 & 11.11 & 10.97 & 10.45 & -20.71 \\
\hline 10 & 2.46 & 2.18 & 2.35 & -7.36 \\
\hline 11 & 4.56 & 4.77 & 4.67 & -13.38 \\
\hline 12 & 3.81 & 3.92 & 3.75 & -11.66 \\
\hline 13 & 9.44 & 9.58 & 9.75 & -19.64 \\
\hline 14 & 3.38 & 3.8 & 3.58 & -11.1 \\
\hline 15 & 2.73 & 3.02 & 2.82 & -9.13 \\
\hline 16 & 5.1 & 5.25 & 5.08 & -14.23 \\
\hline 17 & 6.43 & 6.24 & 6.67 & -16.19 \\
\hline 18 & 1.75 & 1.68 & 1.85 & -4.92 \\
\hline 19 & 3.08 & 3.37 & 3.27 & -10.22 \\
\hline 20 & 5.22 & 4.89 & 5.02 & -14.06 \\
\hline 21 & 7.26 & 7.02 & 6.98 & -17.01 \\
\hline 22 & 3.97 & 3.82 & 3.85 & -11.78 \\
\hline 23 & 1.95 & 2.02 & 1.91 & -5.85 \\
\hline 24 & 2.23 & 2.45 & 2.17 & -7.18 \\
\hline 25 & 4.12 & 4.35 & 4.21 & -12.52 \\
\hline
\end{tabular}

It can also be seen from the Fig. 3 that, the resistance $\mathrm{R}_{1}, \mathrm{R}_{2}$ and spindle speed have the best value, too small or too big of these three machining parameters would reduce the machining efficiency, cause the machining time increase. This is because in this new machining process resistance $R_{1}$ determines the discharge off time and discharge frequency, if the $R_{1}$ is too small, the discharge off time is small witch would raise the unstable discharge phenomena, causing the machining efficiency would be decreased. While the $R_{1}$ is too big, the discharge frequency is reduced greatly, which causing the reduction of machining efficiency. If the resistance $\mathrm{R}_{2}$ is small, the frequent extension and extraction with big deviation of the piezoelectric actuator reduces the discharge frequency, and which increase the machining time. While the big $\mathrm{R}_{2}$ would cause the piezoelectric actuator lose the micro regulation function, and which increase the unstable discharge phenomena, then the machining time increases. The revolving spindle can decrease the unstable discharge phenomena and increase the machining efficiency. The low rotate speed has small effect on the discharge state, and the high rotate speed would cause the electrode collide with the workpiece which cause short-circuit occur, and the high rotate speed of the spindle would lead to the bigger diameter of the machined hole, so the machining time would increase. 


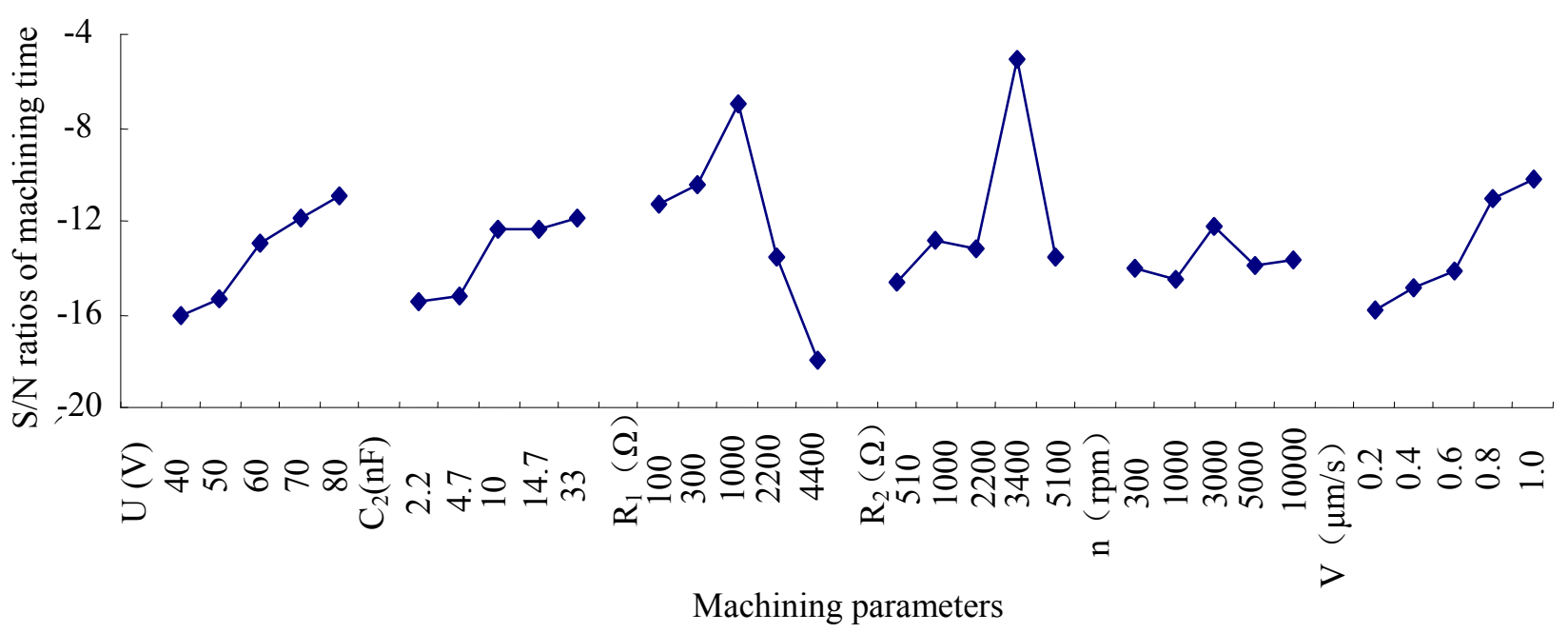

Fig. 3 Machining parameters $\mathrm{Vs} \mathrm{S} / \mathrm{N}$ ratio of machining time

\section{Conclusions}

A new piezoelectric self-adaptive micro-EDM technology was presented in this paper; it can realize self-elimination of short circuits and regulate the discharge gap depending on the discharge state. In this work, a study on the influence of the most relevant piezoelectric self-adaptive micro-EDM factors over the machining time has been carried out. and the following important conclusions are drawn from this investigation:

$>$ With the increase of open voltage, capacitance $\left(\mathrm{C}_{2}\right)$ and initial feeding speed, the machining time decreases.

$>$ The influences of resistance $\mathrm{R}_{1}, \mathrm{R}_{2}$ and rotational speed of spindle on machining time have the best value; the value of these machining parameters can not be too small or too large.

\section{References}

[1] Yu Z Y, Rajurkar K P, Shen H. High Aspect Ratio and Complex Shaped Blind Micro Holes by Micro EDM. CIRP Annals-Manufacturing Technology, 2002,51: 359-362.

[2] Egashira K, Matsugasako A, Tsuchiya H, etc, Electrical discharge machining with ultralow discharge energy. Precision Engineering, 2006,30: 414-420.

[3] Hung Sung Liu, Biing Hwa Yan, Chien Liang Chen, etc. Application of micro-EDM combined with high-frequency dither grinding to micro-hole machining. International Journal of Machine Tools \& Manufacuture. 2006,46: 80-87.

[4] Y.S. Wong, M. Rahman, H.S. Lim, etc. Investigation of micro-EDM material removal characteristics using single RC-pulse discharges. Journal of Materials Processing Technology. 2003,140: 303-307.

[5] J.L. Lin, K.. S. Wang, B.H. Yan, etc. optimization of the electrical discharge machining process based on the Taguchi method with fuzzy logics. Journal of Materials Processing Technology. 2000,102: 48-55.

[6] Yan-Cheng Lin, Yuan-Feng Chen, Der-An Wang, etc. optimization of machining parameters in magnetic force assisted EDM based on Taguchi method. Journal of Materials Processing Technology. 2008 